\title{
Leer
}

\section{Emerson, Leo Strauss, Harold Bloom}

\author{
Dr. Antonio Lastra*
}

\section{Resumen:}

Este artículo ofrece una lectura comparada, una lectura fuerte, de la escritura constitucional de Emerson y Thoreau, la escritura reticente de Leo Strauss y las pautas revisionistas de Harold Bloom, y discute los conceptos de influencia y canon con el propósito de establecer la posibilidad de la lectura. Este ensayo es una defensa de la ética de la literatura.

Palabras clave: leer, escritura constitucional, ética de la literatura

\section{Abstract:}

This paper is a comparative reading, a strong reading indeed, of the constitutional writing of Emerson and Thoreau, the reticent writing of Leo Strauss and the revisionist ratios of Harold Bloom. Also it disputes the notions of influence and canon and it aims to establish the possibility of reading. This paper is an apology of literary ethics.

Key Words: Reading, Constitutional Writing, Literary Ethics.

* Español. Doctor en Filosofía y profesor de Filosofía en la Enseñanza Secundaria española. Codirector de La Torre del Virrey. Revista de Estudios Culturales (www.latorredelvirrey. es) y traductor, entre otros autores, de Leo Strauss y Stanley Cavell. Sú último libro es Emerson como educador (2007, Madrid: Verbum). E-mail: alastra@contraclave.org. 
Mi residencia era más favorable, no sólo para el pensamiento, sino para la lectura seria, que una universidad y... estuve más que nunca bajo la influencia de los libros... "Esta ventaja he tenido con los libros..., tal placer he experimentado cuando he bebido el licor de las doctrinas esotéricas"... Los libros heroicos, aun cuando estén impresos en los caracteres de nuestra lengua materna, siempre estarán en una lengua muerta para las épocas degeneradas y tendremos que buscar laboriosamente el significado de cada palabra y verso, conjeturando un sentido más amplio del que permite el uso común por nuestra sabiduría, valor y generosidad... Leer bien, es decir, leer verdaderos libros con un espíritu verdadero, es un noble ejercicio... Los libros deben ser leídos tan deliberada y reservadamente como fueron escritos. $\mathrm{Ni}$ siquiera es suficiente ser capaz de hablar la lengua de la nación en la que están escritos, pues hay un intervalo memorable entre la lengua hablada y la escrita, la lengua oída y la lengua leída. La primera es, por lo general, transitoria, un sonido, un habla, sólo un dialecto... La segunda es la madurez y la experiencia de la primera; si aquélla es nuestra lengua materna, ésta es nuestra lengua paterna, una expresión reservada y selecta, demasiado significativa para que los oídos la oigan, y tendríamos que volver a nacer para hablarla.... Lo que la multitud romana y griega no pudo oír, algunos escolares lo leyeron tras el intervalo de las épocas, y sólo algunos escolares siguen leyéndolo... La humanidad no ha leído las obras de los grandes poetas, pues sólo los grandes poetas pueden leerlas... Ni siquiera los que llamamos buenos lectores han leído los mejores libros... La mayoría de los hombres no sabe que otra nación, salvo la hebrea, tenga su escritura... No todos los libros son tan torpes como sus lectores... Quizá exista el libro que nos explique nuestros milagros y revele otros nuevos... Es hora de que las ciudades sean universidades... Ésa es la escuela poco común que necesitamos (Thoreau, 2007³: 146-155). 


\section{Introducción}

Podemos leer entre líneas el capítulo sobre la lectura de Walden de Thoreau y extractar esta larga y memorable serie de citas, aunque ni "Leer" ni Walden sean en sí mismos textos originales, de modo que nos sirvan de introducción a la lectura de los textos de Ralph Waldo Emerson, Leo Strauss y Harold Bloom, y a la relación entre esos textos, que quisiera establecer en estas páginas, concebidas, en parte, como un simple comentario de texto. La originalidad o la autoridad del texto literario que sirve de fuente a un comentario son un misterio y un problema que la lectura y la literatura comparada no han logrado desvelar ni resolver nunca por completo, y seguramente tendríamos que volver a nacer para lograrlo, como intuía Thoreau cuando, en uno de los pasajes cruciales del libro, en el capítulo sobre la "Soledad", se refirió enigmáticamente a su relación con el "viejo colono y propietario original" de Walden, que era y no era a la vez Emerson, propietario real de la parcela de tierra donde Thoreau había fijado su residencia. "Aunque se cree que ha muerto -añadía Thoreau- nadie podría mostrar dónde está enterrado." En su vecindad vivía también una "anciana dama" (la naturaleza), cuya memoria se remontaba "más allá de la mitología" y que era capaz de contarle a Thoreau "el original de cada fábula". Pasajes como éste, y todo el capítulo sobre la lectura, constituyen lo que Thoreau llamaría "revisar la mitología". Su residencia era, en efecto, más favorable para el pensamiento y la lectura seria que cualquier universidad.

2. La lectura entre líneas de "Leer" anuncia casi todas las preocupaciones de la teoría contemporánea de la literatura, eminentemente universitaria, respecto a la prioridad textual, la inexistencia del autor o del texto, la diferencia entre la voz y la escritura, la imposibilidad de leer o de encontrarnos en algún lugar o en algún momento fuera del texto, la lectura recíproca y exclusiva de los grandes poetas, e incluso los criterios de corrección política y el elitismo de las humanidades, entre otras preocupaciones, sin embargo, completamente ajenas a Thoreau, que a menudo hacía algo mejor y que, a diferencia de los partidarios de la deconstrucción, solía dejar un amplio margen en su vida antes que en su filosofía. "Lector" es en Walden sinónimo de "estudiante" y de "visionario". El capítulo que sigue a "Leer" y que, de acuerdo con la escritura revisionista de Thoreau, lo corrige, se llama "Sonidos" y anima a leer la lengua "sin metáfora" del hado. Leer es, por sí mismo, una revisión de la mitología, de la razón de ser de los textos, de su propia condición literaria en relación con la vida: leer deliberadamente es vivir deliberadamente. (A "Sonidos" le sigue "Soledad". La revisión de la mitología de Thoreau podría servir de pauta a las pautas revisionistas de Bloom en La ansiedad de la influencia.) 
¿Es "Leer", "Reading", con esta perspectiva, una interpretación o "misreading" -o "misprision", de acuerdo con los términos de Bloom, que podríamos traducir también por "malentendido" o "tergiversación" e incluso por "mala lectura", aunque difícilmente en este caso, que se correspondería más bien con una "strong reading" o "lectura firme"- y el ejemplo por antonomasia de la "ansiedad de la influencia" de uno de esos textos, "El escolar americano" de Emerson, susceptible además, como hemos visto, de una lectura entre líneas, según Leo Strauss sugería que habían de leerse determinados libros durante las épocas de persecución y de censura? En "Leer", Thoreau no se refería sólo a la lectura de otros libros o escritores -entre los que cita, no del todo arbitrariamente, a Homero, Esquilo, Virgilio, la Biblia, Dante, Shakespeare y Platón-, sino que descubría la pauta de la propia escritura de Walden y de su lectura posterior, de nuestra propia necesidad de aprender a leer. La insistencia emersoniana de Thoreau en que las ciudades debían convertirse en universidades evocaba, precisamente, una de las categorías de la antigua retórica, actualizada por la escritura constitucional americana, que desplaza continuamente todas nuestras consideraciones del aula al ágora y del ágora al aula. Walden exponía de una manera trascendental las condiciones de posibilidad del regreso a la civilización, que Thoreau consideraba una "transcripción" o traducción de los clásicos. "Ahora soy de nuevo un residente en la vida civilizada." Ese regreso a la civilización, inscrito en el primer párrafo del libro y que se correspondía con la "fe en la resurrección y la inmortalidad" con la que acababa, no difiere esencialmente de la búsqueda romántica de un bien desconocido ni de la ascensión clásica hacia la idea del bien. Emerson y Thoreau son tan románticos como clásicos en este sentido, y no resultaría fácil conjeturar un sentido más amplio del término romanticismo -que ha guiado la teoría de la poesía de Bloom- para "El escolar americano": "No busco lo grande, lo remoto, lo romántico", dirá Emerson. Dónde haya que estar en cualquier época para empezar a leer es, por el contrario, una cuestión previa de la mayor importancia, en parte porque nuestra residencia actual es una extensión cultural de la democracia -en modo alguno en una época de persecución o de censura, al menos en occidente, ni siquiera de "resentimiento", sino constitucional-, y sobre todo porque la universidad ya no es un lugar más favorable que otros lugares públicos o privados para la lectura seria de los mejores libros. El capítulo previo a "Leer" en Walden llevaba por título "Dónde vivía y para qué". En "El escolar americano", Emerson dirá: "Abrazo lo común, exploro y me siento a los pies de lo familiar, de lo inferior". El romanticismo o trascendentalismo americano podría resumirse en la pregunta central de la enseñanza emersoniana: “En realidad, ¿de qué conocemos el significado?". Creo que toda la obra de Bloom es un intento por responder a esta pregunta dotando de contenido a un significado puesto en entredicho por la deconstrucción (Bloom, 1979: 1-37). (En el prefacio a Deconstruction and Criticism, Hartmann afirmaría que para él 
mismo y para Bloom, a diferencia de los otros coautores, practicantes de la deconstrucción -Paul de Man, Jacques Derrida y J. Hillis Miller-, "the ethos of literature is not dissociable from its pathos" (Bloom, 1979: ix).

En una época constitucional, actuar colectivamente, como decía Thoreau, responde al espíritu de nuestras instituciones. Las páginas que siguen responden tanto al espíritu de la institución literaria que se manifiesta en la escritura reticente de Leo Strauss y en el canon de Bloom como al desafío que para esa institución suponen la escritura constitucional o la ética de la literatura de Emerson y Thoreau, un desafío que puede deparar perfectamente una mejora de la institución misma, como de hecho creo que ha sucedido. Emerson se refirió a esa mejora como una "revolución" que tendría lugar mediante la "domesticación gradual de la idea de cultura". "Cultura", más que "poesía" (como en Bloom) o "filosofía" (específicamente "política", como en Leo Strauss), será una de las palabras clave de la escritura constitucional emersoniana, y lo será hasta el final, hasta el gran texto sobre La conducta de la vida, donde "cultura" tendrá un significado equivalente a "Constitución" (Emerson, 2004). ${ }^{1}$ No vivimos en una época de persecución o de censura; irónicamente podríamos decir incluso que ningún gobierno occidental amenaza con prohibir la lectura de los libros, sino que es más bien la propia sociedad civil o liberal la que consiente en que se estén olvidando o diseminando, disminuida su importancia, sobre todo, en su sistema educativo, del que la sociedad no es menos responsable que el gobierno. ¿A quién le corresponde leer? ¿Quién debe leer los libros con la misma deliberación y reserva con que fueron escritos si ni siquiera los que llamamos buenos lectores han leído los mejores libros? La institución literaria es primordialmente una institución de enseñanza, la escuela poco común que -según Thoreau-necesitamos: "Aspiro a tratar con hombres más sabios que los que ha producido esta tierra nuestra de Concord... ¿Oiré el nombre de Platón y no leeré nunca su libro? Es como si Platón fuera un conciudadano mío y nunca lo viera, o vecino mío, y nunca lo oyera hablar ni estuviera atento a la sabiduría de sus palabras". La lectura no es sólo una cuestión de deleite individual,

En vísperas de la Guerra de Secesión -una secesión semántica además de política-, el empleo de los términos constitucionales sustituiría en el léxico emersoniano al término "revolución", que Emerson había empleado hasta entonces. Acabada la guerra, Emerson hablaría del "progreso de la cultura". Véase el poema que sirve de prólogo al capítulo "Cultura" de La conducta de la vida, donde Emerson se refiere a la "suave influencia" de la que es susceptible el "semidiós al que esperamos", y que tanto influiría en Friedrich Nietzsche. (La conducta de la vida, publicado en 1860, era también una lectura de Walden: véase el capítulo dedicado a la "Riqueza".) El uso emersoniano del término "cultura" condiciona favorablemente, en mi opinión, la práctica de los Estudios Culturales: "Un nuevo grado de cultura -escribió en "Círculos"- revolucionaría instantáneamente todo el sistema de las aspiraciones humanas" (Emerson, 1996: 408). 
un juego estético autónomo, como Bloom defiende, sino que también constituye una exigencia de la comunidad. ${ }^{2}$

3. Una tarde del verano de 1837, poco antes de pronunciar el discurso ante la Phi Beta Kappa Society de Cambridge que ahora conocemos como "El escolar americano", Emerson anotó en su diario -donde el discurso iba tomando forma paulatinamente y adquiriendo toda su dimensión inaugural- que había dado un paseo por los bosques de Walden. "El escolar americano" supondría, como Walden, un regreso a la civilización. Entre los asistentes al discurso, pronunciado el 31 de agosto, se encontraba el propio Thoreau, que se había licenciado en la Universidad de Harvard ese mismo año y que, como los otros miembros del recién fundado círculo trascendentalista de Concord, ya había leído para entonces el primer libro de Emerson, Naturaleza, publicado anónimamente el año anterior y donde podía leerse la pregunta inicial de la filosofía en América a la que Walden trataría de dar una respuesta: "¿Por qué no habríamos de disfrutar también nosotros de una relación original con el universo?". En el cuarto capítulo del libro, "Lenguaje", que hoy cobra un valor de lectura extraordinario por la prioridad concedida al significado, Emerson enunciaría -citando tácitamente la autoridad cristiana de George Fox- la ley fundamental de la crítica, según la cual "toda Escritura ha de ser interpretada por el mismo espíritu que la produjo". La Escritura, con mayúscula, se

2 Leo Strauss sugirió que las enseñanzas más importantes respecto a la escritura reticente se encontraban "sepultadas en los escritos de los retóricos de la antigüedad" (Strauss, 1996: 77). Véase, sin embargo, Reyes, 19972: 405: "Que Cicerón y otros muchos hayan ido al Asia Menor por lecciones de oratoria, se explica considerando que en aquellas comunidades griegas las normas democráticas se conservaron prácticamente hasta el primer siglo de nuestra era... La oratoria, pues, conservaba allá su natural ambiente. Sin embargo, la tendencia natural de la retórica... era ya el confinarse dentro de las aulas, alejándose de la vida del pueblo y tipificándose en una pedagogía escolástica que se disputaba con los filósofos la educación de la juventud". (Adviértase el uso equívoco del adjetivo "natural". El artículo "Persecution and the Art of Writing", que daría nombre al libro de Strauss, publicado originalmente en 1952, y La antigua retórica datan ambos de 1941. Una comparación de los dos textos explicaría algunos de nuestros milagros y revelaría otros nuevos.) Sobre "la primera escena de instrucción", véase Bloom, 20032: 41-62; véase también el capítulo previo, "The Dialectics of Poetic Tradition", pp. 26-40, especialmente relevante por la apelación de Bloom a la autoridad de Quintiliano. La escritura constitucional de Emerson y Thoreau permitiría leer lo que podemos llamar la ética de la literatura en Quintiliano -la formación del carácter del orador en paralelo a su formación intelectual- sin incurrir en un estudio de la nostalgia del sistema republicano, fuera del cual el orador estaría condenado a la reticencia. La literatura es siempre original. Véase Inst. Orat., XII, ii, 2-14: “Nos ipsam nunc uolumus significare substantiam, ut grammatice litteratura est, non litteratrix quem ad modum oratrix, nec litteratoria quem ad modum oratoria: uerum id in rhetorice non fit". Agradezco al profesor Till Kinzel que me haya permitido leer su trabajo inédito Die Bedeutung der Redelehrer für die vita activa der Römer. Eine Analyse von Quintilians institutio oratoria und Tacitus' dialogus de oratoribus y a los profesores Salvador Santafé, María Jesús Iniesta e Isabel Martínez su ayuda en la lectura de Quintiliano. 
correspondía con la escritura constitucional. La última exhortación de Naturaleza animaba, en consecuencia, a sus lectores a "construir un mundo propio" (Emerson, 1971: 17-23, 18). ${ }^{3}$

"El escolar americano" ha sido considerado, desde entonces, la Declaración de Independencia literaria, una escritura de enmienda o mejora de la Declaración de Independencia política y de la propia Constitución de los Estados Unidos de América. "Nuestro día de dependencia -diría Emerson en aquella ocasión-, nuestro largo aprendizaje de las enseñanzas de otras tierras, ha terminado." (Thoreau empezaría a vivir en Walden, "por accidente", el 4 de julio de 1845, el día en que se conmemora la Declaración de Independencia. Sobre la prioridad textual de la Declaración de Independencia, véase, en estrecha relación con estas páginas, Derrida, 1984: 11-32.) Sin embargo, Emerson advertiría en seguida cuáles eran las "influencias" que recibía el escolar americano. Es tan difícil no trazar una analogía con el significado que Bloom le ha dado a la palabra como resistirse a su propia influencia.

"La primera en el tiempo y la primera en importancia de las influencias que recibe es la de la naturaleza." Una de las pautas de la escritura emersoniana es la recurrencia de los escritos anteriores en los posteriores, el revisionismo que luego practicará Thoreau en Walden y en Walden. La influencia de la naturaleza es también la influencia de Naturaleza, que empezaba diciendo que "nuestra época es retrospectiva" y acababa con un capítulo llamado "Prospects". Desde el punto de vista de la escritura constitucional o de la escritura prospectiva que mejora el texto original de la comunidad que había creado su propio mundo de lectores, resulta significativo que Emerson dijera que una época retrospectiva es la que erige los "sepulcros de los padres", es decir, de los padres fundadores de la nación. (Herman Melville, que sería el primero en acusar precipitadamente a Emerson de no darse cuenta de la presencia del mal en el mundo, concebiría la escritura como un "epitafio", y es difícil sustraerse a esa impresión cuando leemos Pierre, Moby Dick o Billy Budd.) La influencia de la naturaleza descubre, por el contrario, una raíz común con el hombre, por encima de las circunstancias y de la época. La escritura constitucional emersoniana, que recibe su gracia de la gracia de la naturaleza, tiene que enfrentarse a la influencia, mucho más poderosa, de la historia.

\footnotetext{
"El escolar americano" recibiría este nombre en la reedición en 1849 de Naturaleza y los discursos y conferencias que Emerson había dado hasta la publicación de la primera serie de los Ensayos en 1841. Esta reedición aparecía ya con el nombre del autor. Traduzco Scholar por "escolar", que me parece preferible a "intelectual", "hombre de letras", "filólogo", "escritor" o "filósofo". El profesor Ramón del Castillo me ha sugerido que podría traducirse, de acuerdo con una vieja tradición española, por "maestro", y sin duda Emerson es el Erzieher de sus lectores (véase Lastra, 2007).
} 
A la influencia de la naturaleza le sigue, en efecto, la influencia del pasado. "Los libros -escribió Emerson- son el mejor ejemplo de la influencia del pasado." ¿Cómo leía Emerson? Hacia el final de su vida, Emerson establecería la polaridad entre la "cita" y la "originalidad" que caracteriza al buen lector, que ha de ser un inventor para leer bien y poder tomar en préstamo (Emerson, 1996: 1028-1042). Lo contrario del buen lector sería el "restaurador de lecturas". Leo Strauss y Bloom, buenos y hasta excelentes lectores, serían, sin embargo, restauradores de lecturas según la teoría emersoniana de los libros. Los libros ejercen noblemente toda la influencia del pasado, aunque Emerson sería reacio a aceptar su influencia, poniendo de relieve precisamente la actitud que Bloom ha diagnosticado como "ansiedad de la influencia": "Preferiría -dice Emerson- no haber visto nunca un libro que desviarme de mi órbita a causa de su atracción". Su peculiar "lectura entre líneas", a la que aludiría en "Cita y originalidad", tendría que permitirle descubrir en los libros "cosas mejores que las que escribió el autor", aunque no desvelar el misterio de la lectura -el problema de la prioridad o la autoridad irremisiblemente perdida- que anotaría en un pasaje de su diario, poco antes de pronunciar el discurso sobre "El progreso de la cultura" con el que, treinta años después de haber sido vetado en la Universidad de Harvard, volvía a dirigirse al público universitario:

Leer. Creo que cualquier viejo escolar habrá tenido la experiencia de leer en un libro algo que era significativo para él y que no ha vuelto a encontrar; está seguro de haberlo leído, pero nadie más lo ha hecho y él mismo no puede encontrarlo, aunque rebusque en cada página ( 2 de julio de 1867, Emerson, 2006; 1894: 473-484).

Esa experiencia simultánea de sentido y de pérdida del sentido, de presencia y de ausencia -teñida incluso con la melancolía del final de su vida como lector-, señala más que ninguna otra experiencia la creación y el límite del genio de la lectura. "El genio es siempre el enemigo del genio por un exceso de influencia", dirá Emerson en "El escolar americano". El exceso de influencia o la ansiedad de la influencia indicarían para Emerson un modo inadecuado de leer. Emerson preconizaría una lectura creativa análoga a una escritura creativa. La lectura creativa discierne en los libros "las auténticas expresiones del oráculo" y desecha lo demás. La lectura creativa capta todo el significado de la escritura reticente y logra ponerse a salvo de la influencia. Bloom negará y reafirmará esa salvación cuando hable de la lucha de un significado contra otro que suscita la ansiedad.

Las influencias de la naturaleza y del pasado preceden a la influencia de la acción. Juntas proporcionan la "educación" del escolar. La educación del escolar sometido a las influencias de la naturaleza, el pasado y la 
acción le impone una serie de obligaciones, la principal de las cuales es "la confianza en sí mismo", en la que se reúnen todas las virtudes. En "El escolar americano", confianza en sí mismo es "Self-trust", "self-relying" y "confidence in himself". En la primera serie de los Ensayos (publicada en 1841), Emerson preferirá "Self-Reliance", y "Confianza en sí mismo", el segundo de los ensayos tras "Historia", constituirá el primer gran ejemplo de la escritura emersoniana: “El otro día leí -dirá Emerson en la primera línea del ensayo- algunos versos escritos por un pintor eminente que eran originales y no convencionales". (La primera línea del ensayo de Emerson es significativa. En el diario, el término original era "Self-respect", una lectura a su vez de la "Acquiescence" o "Patience" de los cuáqueros. A "Confianza en sí mismo" le sigue el gran ensayo sobre la "Compensación", donde Emerson dirá que lo mejor del escritor es lo menos privado. Véase Emerson, 1996: 259-282; Cavell, 2003). Los Ensayos fueron el primer libro publicado con el nombre propio de Emerson. La originalidad, la autoridad, el inconformismo, la independencia, la confianza en sí mismo y en su escritura se oponían en él a la lectura "mendicante y servil". La confianza en sí mismo era también la aversión de la sociedad en la que Stanley Cavell ha visto la condición menos favorable de la filosofía emersoniana. Un pasaje del diario, escrito poco antes del Discurso a la Facultad de Teología que le acarrearía el veto en la Universidad de Harvard y supondría el desplazamiento de la escritura emersoniana del púlpito y el aula al ágora, fija los términos de la polaridad de la sociedad y la soledad de la escritura emersoniana: "En el jardín, el ojo observa las nubes pasajeras y los bosques de Walden, pero evita la ciudad. ¡Pobre sociedad! ¿Qué has hecho para ser la aversión de todos nosotros?" (24 de junio de 1838). La naturaleza pública de la escritura emersoniana trascendía el rechazo institucional y dejaba a la sociedad expuesta a la libre apariencia de las palabras de Emerson. La confianza en sí mismo contrarrestaría el pesar que procuraba cada una de las palabras sociales -convencionales, conformistas, dependientes de instituciones- y mejoraría la identidad original del público sobre la que recae la confianza universal del escritor. La argumentación emersoniana, tradicionalmente considerada aforística y laxa, es, por el contrario, coherente e indestructible. Su premisa es superior a cualquier sensación de ansiedad y se apoya en la libertad y valentía del escolar. Lo contrario de la confianza en sí mismo sería, en efecto, la cobardía. La cobardía nace de la idea errónea de que hemos llegado tarde o de que no podemos expresarnos con libertad, de que "nos detienen -como dirá Emerson- las segundas intenciones". Por el contrario, el escolar, el escolar americano y, en mi opinión, cualquier lector y escritor constitucionales, asumirán todas las contribuciones del pasado y harán suyas todas las esperanzas del futuro. La domesticación de la idea de cultura es genuinamente revolucionaria y se propone "la conversión del mundo". El primer principio de la ética de la literatura es que la literatura aún está por escribir. 
4. Stanley Cavell ha insistido en numerosas ocasiones en que no se ha "oído" filosóficamente a Emerson, a diferencia de la lectura o interpretación poética que Bloom ha señalado como característica de la literatura americana. En los términos de la escritura constitucional en los que querría expresarme aquí, la ausencia o la influencia de Emerson coincidirían con la ausencia o la influencia de América como un término significativo para la literatura y la filosofía posteriores. Emerson significa América. Leer a Emerson es leer el texto de la nueva e inalcanzable América. En este sentido, tiene razón John Hollander cuando escribe que La ansiedad de la influencia "podría haberse leído como una serie de prolegómenos a un nuevo estudio de América". Si bien Los poemas de nuestro clima, el libro de Bloom sobre Wallace Stevens, corroboraría esta interpretación -en mi opinión se trata de la obra maestra absoluta de Bloom-, Hollander parece referirse a otra clase de estudio, en la línea de los grandes estudios americanos de Perry Miller y F. O. Matthiessen, sobre la "secundariedad" de la escritura americana. Al margen de la disputa entre la poesía y la filosofía -de la que Bloom descreería y que constituye uno de los capítulos más intrincados de la obra de Leo Strauss-, La ansiedad de la influencia comparte con Persecución y arte de escribir la responsabilidad de un discurso eminentemente conservador, más en lo que concierne a la ética de la literatura que a la política, sobre la formación del canon en la historia y la posibilidad de decir la verdad y la continuidad misma del relato o de las narraciones humanas, en el que "América" no llegará a ser nunca un trasfondo adecuado. Desde el punto de vista de los Estudios Culturales nos encontraríamos en la provincia de la ecología de la cultura si no fuera porque ni Leo Strauss ni, en última instancia, Bloom aceptarían que el orden humano de la producción, al que responde la cultura, pueda confundirse con el orden divino de la creación, al que le corresponde la primera y la última palabra (Bloom, 1988: xvii, xx, xxviii; Altini, 2001: 10-11). ${ }^{4}$

La revelación de un texto original es decisiva para el judaísmo. Bloom ha proyectado sobre el judaísmo, en lo que tal vez sea el mayor "encuentro de lecturas" de su obra, una ansiedad de la influencia mayor que sobre la poesía secular. Aunque no haya otro texto cuya lectura sea tan "firme" como la Biblia hebrea, la pérdida de la identidad de los judíos americanos se debe, según Bloom, a que ya no se percibe una diferencia textual significativa con la literatura gentil, como si el Deuteronomio y la Constitución fueran equivalentes o pudiera establecerse entre ellos una

4 La relación de Bloom con Hollander-un encuentro de lectores igualmente fuertes- merecería un ensayo aparte. Bloom ha sido -según Hollander- "el mejor amigo y el crítico más severo de mi poesía, no sólo el crítico de mi poesía sino su amigo" (Hollander, 1998: 171-4; 1974). 
correlación interpretativa errónea, una misreading. "La vieja fórmula del Galut -ha escrito Bloom- ya no funciona en los difusos contextos culturales de América." Los judíos no escriben los poemas de nuestro clima (Bloom, 1988: 355-57). ${ }^{5}$

No es probable que Leo Strauss hubiera suscrito la conclusión de Bloom respecto a que "ya no estamos en el exilio". (El sujeto de la frase sería "Nosotros, los judíos americanos".) La escritura reticente, por el contrario, es la expresión por antonomasia del exilio, del desplazamiento o de la incomunicación entre una parte de la sociedad minoritaria e intransigente en su búsqueda de la verdad, constituida por los filósofos, y la mayoría social -cualquiera que sea la sociedad de la que formen parte- obediente a las costumbres y creencias ancestrales. ${ }^{6}$ Es posible que, en Persecución y arte de escribir, los falãsifa -según la transcripción arábiga de la palabra griega para "filósofos" que Leo Strauss emplea- sean, respecto a las sociedades del pasado que Leo Strauss estudia como historiador, un trasunto del pueblo judío respecto a la humanidad. La célebre contraposición de Atenas y Jerusalén sería, de este modo, una sutil superposición destinada a encubrir la profunda desconfianza de Leo Strauss en la sociedad liberal. Un filósofo genuino no podría convertirse nunca en un creyente genuino de ninguna religión revelada y tampoco en un ciudadano genuino de ninguna sociedad. Sin embargo, una sociedad liberal no es exactamente lo mismo que una sociedad constitucional. (La polémica entre Edmund Burke y Thomas Paine a propósito de los derechos del hombre muestra de una manera paradigmática la diferencia entre ambas sociedades. Véase también Hegel, 2005, especialmente hacia el final. La última palabra del texto hegeliano es "revolución".) Leo Strauss trasladó a la sociedad constitucional americana su desconfianza de la sociedad liberal europea, y no sólo de la sociedad totalitaria en la que veía el estadio final inevitable de la sociedad liberal. Sin embargo, el estudio sobre la persecución y la escritura reticente no es sólo un estudio histórico, sino un principio de entendimiento. Para empezar a entender la sociedad en la que se había exiliado, Leo Strauss tuvo que empezar por sentirse extraño en ella. Los falãsifa habían insistido en comparar la vida filosófica con la vida retirada y contemplativa del eremita que salvaguardaba la independencia intelectual. El estudio de la escritura reticente trascendía, por tanto, "los límites de la estética moderna y de

En el prólogo a Zakhor, Bloom incurriría en su propia ansiedad de la influencia en el encuentro de lecturas americanas y judías: "No sabremos qué es y qué no es contemporáneo en la cultura judía hasta que lo examinemos retrospectivamente" (Bloom, 1989: xx).

6 Véase Strauss, 1988 a: 299: "Platón sustituye la ley que fija la creencia en la existencia de los dioses de la ciudad de Atenas por una ley que fija la creencia en la existencia de los dioses del universo, poniendo así el fundamento de la libertad de la filosofía socrática, si no de la libertad de la filosofía como tal". 
la poética tradicional" y se convertía en un estudio de filosofía política: el estudio del conflicto entre los tradicionalistas y los críticos dotados de pautas de juicio superiores e inalterables. En cualquier sociedad, y también en una sociedad constitucional, la libertad de investigación y la publicación de los resultados de la investigación, serían, cuando menos, arriesgadas, según Strauss, y no estarían garantizadas por completo, lo que obligaría a practicar una "literatura exotérica". La literatura exotérica tiene que ser capaz de impartir sus enseñanzas a pesar de la inferioridad de la escritura respecto a la transmisión oral del texto original, es decir, de la Escritura en un sentido eminente confiada a unos pocos. La lectura del texto original precede a la escritura reticente. Maimónides, por ejemplo, habría escrito su Guía de perplejos de acuerdo con las mismas reglas que había prescrito para leer la Biblia. Los Diálogos de Platón proporcionarían la fuente clásica de la literatura exotérica.

La escritura reticente trata de impedir la lectura efectiva de los censores y se dirige a los futuros falãsifa, que aún no son los iguales del filósofo. La escritura reticente ejerce sobre los futuros falãsifa la influencia de la filosofía. La influencia de la filosofía consiste en llevar al lector inteligente y digno de confianza a separarse de sus propias opiniones, a mirar las cosas no desde el punto de vista habitual sino con la perspectiva central de la enseñanza influyente. La influencia de la filosofía significa la conversión a la filosofía, a la búsqueda intransigente de la verdad sobre las cosas más importantes y lo más importante de todas las cosas. La escritura reticente de la filosofía implica, sin embargo, que, "en la actualidad, la verdad sólo resulta accesible mediante algunos viejos libros". La escritura reticente es un procedimiento de enseñanza de la lectura de los libros que franquean el acceso a la verdad.

El acceso a la verdad depende, en última instancia, del acceso al significado original de la filosofía como una búsqueda de la verdad y de la explicación coherente y definitiva del conjunto de las cosas. El historicismo, que concibe el acceso a la verdad como algo progresivo y como el resultado, proyectado hacia el futuro, de la cultura de la razón, impide que la idea de esa explicación final tenga sentido. Una vez se llega a esta situación, que para Strauss era la situación de la época moderna en la que las sociedades liberales, totalitarias o democráticas, se encontraban, "el significado original de la filosofía sólo sería accesible mediante el recuerdo de lo que la filosofía significaba en el pasado", es decir, mediante la lectura de los viejos libros. El significado original de la filosofía es más importante que la originalidad de los filósofos. Cuando el filósofo recuerda el olvidado modo de escribir con que se escribieron los viejos libros, la lectura de esos viejos libros adquiere un valor superior al del establecimiento de un nuevo sistema de filosofía (Strauss, 1988 a: 221-232). 
5. Tanto Persecución y arte de escribir como La ansiedad de la influencia causaron la impresión, cuando aparecieron, de ser-como Hollander ha señalado- textos "salvajes y extremadamente erráticos", si bien la idea central de ambos libros ha acabado disolviéndose en el lenguaje contemporáneo de la filosofía política y la teoría de la poesía, a menudo de una forma inconsciente e involuntaria. Leo Strauss diría que, al menos, sus observaciones sobre la escritura reticente habrían de servir para que los historiadores abandonaran la complacencia con la que pretendían conocer lo que pensaban los grandes pensadores y admitieran que el pensamiento del pasado es mucho más enigmático de lo que suponían. El acceso a la verdad histórica -como afirmó al final de "Sobre un modo olvidado de escribir"- es tan difícil como el acceso a la verdad filosófica.

Retrospectivamente, Bloom ha señalado que La ansiedad de la influencia (o, como la llama en el prefacio a la segunda edición, la "angustia de la contaminación") se ha malinterpretado desde el principio y sigue malinterpretándose. Es probable que a esta mala lectura haya contribuido la violencia hermenéutica con la que Bloom ha acabado por transformar su teoría de la poesía en el "canon occidental" y erigido a Shakespeare -una figura secular- en el centro del canon. Sin embargo, el carácter psicológicamente "irresistible" que Bloom le ha dado a la ansiedad de la influencia hace de su lectura una toma de partido. Bloom siempre ha escrito de una manera antitética, contra sus maestros, como advierte HoIlander, y contra sus lectores. El estudio de la ansiedad de la influencia no es, por ello, un estudio sereno sobre las fuentes literarias o la historia de las ideas, sino que pone de relieve, como la escritura reticente straussiana, un malestar profundo que rara vez aflora a la superficie salvo cuando el fondo se remueve. Su delimitación al terreno de la poesía, especialmente de la poesía romántica inglesa y americana, no debe hacernos olvidar que está en juego algo más que la autonomía estética. A diferencia de la escritura reticente de Leo Strauss, que no puede desprenderse de su carácter educativo en la medida en que se dirige a lectores que aún no son los iguales de los escritores, el espectáculo de la batalla entre iguales, e igualmente fuertes, que la ansiedad de la influencia pone ante los ojos del lector corre el riesgo de suscitar el resentimiento de quien se considera fuera del campo de batalla y, sin embargo, se sabe menos a salvo que los propios contendientes. "Averiguar dónde estamos-escribe Bloom-es la más sombría de nuestras indagaciones, y la más fatídica", en la medida en que podríamos estar fuera del texto original y de su influencia. Los poetas ni siquiera necesitan leer tan firmemente como los críticos. Para los poetas, la poesía ya está escrita en el lenguaje mismo de la influencia y sólo se trata de dejarse encontrar por los poemas. La influencia poética es un modo de la perversión. 
Las pautas revisionistas establecidas por Bloom en La ansiedad de la influencia y Un mapa de la interpretación -Clinamen o ironía, Tessera o sinécdoque, Kenosis o metonimia, Demonización o hipérbole, Ascesis o metáfora y Apofrades o metalepsis- pueden llevarnos a la tautología y el silencio. En el capítulo emersoniano del libro, "Demonización”, Bloom se revuelve contra su maestro, y Un mapa de la interpretación es el intento, profundamente antagónico, de "invertir" a Emerson por completo. La escritura y la lectura se convierten en un proceso de sacrificio: "Hemos institucionalizado -dirá irónicamente Bloom- los procedimientos emersonianos". En lo que constituye un anuncio de su libro sobre Wallace Stevens, Bloom cita en la última página dedicada a la Ascesis la "búsqueda de un ser humano del que se pueda dar una explicación", que emprende el nuevo escolar que sustituye al antiguo. Bloom sería el nuevo escolar americano que sustituyera a Emerson. Pero la sustitución está teñida de la melancolía que suscita la ansiedad de que ya no le quede nada por hacer, de que la literatura ya no haya de ser escrita sino que esté ya escrita, de que siempre haya estado escrita. La ansiedad de la influencia pervierte, en efecto, el sentido de la originalidad de la literatura. Si la literatura ya está escrita, si de algún modo siempre lo ha estado, no tiene sentido leerla.

\section{Conclusión}

A la ansiedad de la influencia y a la sensación de impotencia le corresponden un tono elegíaco. La revisión de La ansiedad de la influencia y Un mapa de la interpretación enseña a leer el poema de Milton Lycidas, "la elegía central del lenguaje", y es probable que el propio Bloom pase a la historia de la literatura como un gran escritor elegíaco. Si no un buen lector en el sentido emersoniano, Bloom es desde luego un buen restaurador de lecturas. Un buen restaurador de lecturas no puede llegar demasiado tarde si quiere que su tarea tenga sentido, y a veces da la impresión de que Bloom prefiere que no tenga sentido. Un buen restaurador de lecturas no tiene necesidad de "desmitologizar" y privar de su carácter esotérico a su propia perspectiva sobre la tradición. Ni Thoreau ni Leo Strauss tuvieron la necesidad de hacerlo. La lectura no era imposible para ellos. "Aunque soy un inquieto buscador de significados perdidos -respondería Bloom-, llego a la conclusión de que prefiero un tipo de interpretación que trate de restaurar el significado, y rendirle justicia, a deconstruir el significado." Es una tardía enseñanza emersoniana.

\section{Referencias}

Altini, Carlo (2001),

"Leo Strauss y el canon occidental. La historia de la filosofía como modelo hermenéutico para la 
filosofía política", trad. de M. Vela Rodríguez, en Res publica. Revista de la historia y el presente de los conceptos políticos, 8, pp. 10-11.

Harold Bloom, Paul de Man, Jacques Derrida, Geoffrey H. Hartman, J. Hillis Miller (1979), Deconstruction and Criticism, New York: The Seabury Press.

(1988),

(1989),

(2003)

Cavell, Stanley (2003),

Derrida, Jacques (1984),
(1996),

(2003)

Poetics of Influence, New and Selected Criticism, edited and with an Introduction by John Hollander, New Haven: Henry R. Schwab.

"Foreword", en Yerushalmi, Yosef Hayim, Zakhor. Jewish History and Jewish Memory, Washington: University of Washington Press.

The Anxiety of Influence. A Theory of Poetry, Second Edition. New York \& Oxford: Oxford UP.

A Map of Misreading, with a New Preface, New York \& Oxford: Oxford UP.

Emerson's Transcendental Etudes, ed. by D. J. Hodge, Stanford: Stanford UP.

"Déclarations d'Independence", en

Otobiographies. L'enseignement de Nietzsche et la politique du nom propre, Paris: Galilée.

Emerson, Ralph Waldo (1894), "The Progress of Culture. Address read before the Phi Beta Kappa Society at Cambridge, July 18, 1867", Works of Ralph Waldo Emerson, London: Routledge, pp. 473-84.

Nature, Addresses, and Lectures, Introductions and Notes by Robert E. Spiller, Text established by Alfred R. Fergusson, The Collected Works of Ralph Waldo Emerson, vol. I, Cambridge, Mass.: The Belknap Press of Harvard University Press.

Essays \& Poems, ed. by J. Porte, H. Bloom and P. Kane, New York: The Library of America, College Edition.

The Conduct of Life, Introduction by Barbara L. Packer, Notes by Joseph Slater, Text Established by Douglas Emory Wilson, The Collected Works of Ralph Waldo Emerson, vol. Vl, Cambridge, Mass., and London: The Belknap Press of Harvard University Press. 
(2006),

(2008),

Hegel, G. W. F. (2005),

Hollander, John (1998), (1974),

Lastra, Antonio (2007),

Reyes, Alfonso (1997²),

Strauss, Leo (1988 a),

(1988 b)

(1996),
The Digital Journals of Ralph Waldo Emerson, New York: The Ralph Waldo Emerson Institute.

Naturaleza y otros escritos de juventud, ed. de J. Alcoriza y A. Lastra, Madrid: Biblioteca Nueva.

Sobre el proyecto de reforma inglés. El debate de 1831 sobre el Derecho electoral británico, ed. de E. Maraguat, Madrid \& Barcelona: Marcial Pons.

The Poetry of Everyday Life, Ann Arbor: The University of Michigan Press.

The Head of the Bed, with a commentary by Harold Bloom, Boston: David R. Godine.

Emerson como educador, Madrid: Verbum.

La antigua retórica, en Obras Completas, vol. XIII, México: FCE.

What is Political Philosophy? and Other Studies, Chicago \& London: The University of Chicago Press.

Persecution and the Art of Writing, Chicago \& London: The University of Chicago Press.

Persecución y arte de escribir y otros ensayos de filosofía política, ed. de A. Lastra, Valencia: Edicions Alfons el Magnànim.

Thoreau, Henry David (2004), Walden, The Writings of Henry David Thoreau, $150^{\text {th }}$ Anniversary Edition, ed. by J. Lindon Shanley with an Introduction by John Updike, Princeton \& London: Princeton UP.

Walden $\left(2007^{3}\right), \quad$ Walden, ed. de J. Alcoriza y A. Lastra, Madrid: Cátedra. 